\title{
Spectroscopic properties of a family of mono- to trinuclear lanthanide complexes ${ }^{\mathrm{i}}$
}

\author{
Mohamadou Sy ${ }^{\mathrm{a}}$, David Esteban-Gómez ${ }^{\mathrm{b}}$, $\underline{\text { Carlos Platas-Iglesias }}^{\mathrm{b} *}$ Aurora Rodríguez-Rodríguez $^{\mathrm{b}}$, \\ Raphaël Tripier ${ }^{\mathrm{c}}$, Loïc J. Charbonnière ${ }^{\mathrm{a} \dagger}$ \\ a Laboratoire d'Ingénierie Moléculaire Appliquée à l'Analyse, IPHC, UMR 7178 CNRS, Université de Strasbourg, \\ ECPM, Bât R1N0, 25 rue Becquerel, 67087 Strasbourg Cedex, France

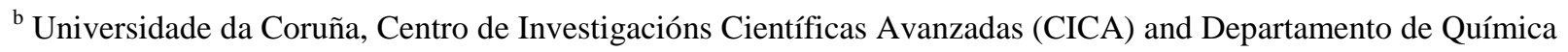 \\ Fundamental, Facultade de Ciencias, 15071 A Coruña, Galicia, Spain \\ ${ }^{c}$ Université de Bretagne Occidentale, UMR-CNRS 6521/SFR ScInBioS, 6 avenue Victor le Gorgeu, C.S. 93837 , \\ 29238 Brest Cedex 3, France
}

European Journal of Inorganic Chemistry, volume 2017, issue 14, pages 2122-2129, 10 April 2017

Received 19 December 2016, accepted manuscript online 15 February 2017, version of record online 13 April 2017, issue online 13 April 2017

This is the peer reviewed version of the following article:

Sy, M., Esteban-Gómez, D., Platas-Iglesias, C., Rodríguez-Rodríguez, A., Tripier, R. and Charbonnière, L. J. (2017), Spectroscopic Properties of a Family of Mono- to Trinuclear Lanthanide Complexes. Eur. J. Inorg. Chem., 2017: 2122-2129

which has been published in final form at https://doi.org/10.1002/ejic.201601516. This article may be used for non-commercial purposes in accordance with Wiley Terms and Conditions for Use of Self-Archived Versions.

\begin{abstract}
A series of mono-, di-, and trinuclear complexes of $\mathrm{Eu}$ and $\mathrm{Tb}$ was designed to study the influence of the number of $\mathrm{Ln}$ emitting centers on the luminescence properties of discrete polynuclear complexes. The complexes are based on a cyclen scaffold, functionalized by two picolinic acid pendant arms. These coordinating units are separated by a 1,3-dimethylbenzene spacer for the dinuclear complex and a 1,3,5trimethylbenzene bridge in the case of the trinuclear complex. The synthesis and characterization of the ligands are presented, together with the preparation and spectroscopic characterization of the complexes. The luminescence properties of the complexes were determined by UV/Vis absorption spectroscopy and steadystate and time-resolved luminescence spectroscopy in buffered aqueous solutions. Comparison of the electronic absorption spectra showed that the absorption properties can almost be considered as extensive parameters within experimental error, as expected for electronically non-conjugated systems. A small drop of both the excited state luminescence lifetimes and the luminescence quantum yields was observed for the trinuclear complexes in the case of $\mathrm{Tb}$. To understand this behavior, theoretical HF (Hartree-Fock) calculations were performed for the three complexes. Models indicate that the average intermetallic distance in the dinuclear complex is almost the same as in the trinuclear one, disfavoring a possible distance dependence of the observed phenomena.
\end{abstract}

Keywords: lanthanides; luminescence; polynuclear complexes; macrocyclic ligands; UV/Vis spectroscopy

\footnotetext{
* carlos.platas.iglesias@udc.es

†1.charbonn@unistra.fr
} 


\section{Introduction}

There are many criteria to unravel the success of a luminescent probe, such as its user friendliness, its price, or even, subjectively, its color. Among the various criteria, the brightness, defined by the product of the molar absorption coefficient and the luminescence quantum yield, ${ }^{[1]}$ is evidently the most scientifically relevant parameter. The former term quantifies the ability of the probe to collect photons, the latter is related to its potential to restore them in the form of photons. Whereas fluorescent dyes or semiconducting nanocrystals can reach brightness values higher than $10^{5} \mathrm{~m}^{-1} \mathrm{~cm}^{-1},{ }^{[2]}$ luminescent lanthanide (Ln) complexes generally display less than tens of thousands units in the best cases. ${ }^{[3-5]}$ Nevertheless, lanthanide-based probes present other beneficial aspects that, in part, compensate this drawback. They display large (pseudo-) Stokes shifts, elemental spectral signatures, ${ }^{[6]}$ and may be used in time-resolved detection modes to improve the signal to noise ratio thanks to their long excited-state lifetimes. ${ }^{[7,8]}$

Efficient excitation of luminescent lanthanide complexes is obtained by the use of antenna ligands, which collect photons and transfer the energy to the lanthanide ion. The optimization of the brightness of such complexes requires the optimization of both the absorption of the ligands, the ligand to metal energy transfer process, and the Ln-centered luminescence quantum yield. ${ }^{[9]}$ Different approaches have been developed to increase the metal-centered quantum yield by protection of the metal ion from solvent molecules, ${ }^{[10,11]}$ or deuteration of the ligands, ${ }^{[12,13]}$ as well as to optimize the ligand to metal energy transfer for $\mathrm{Eu}$ and $\mathrm{Tb}$ cations. ${ }^{[14-16]}$ However, increasing the absorption coefficient of the antenna is subject to some theoretical limitations. Very large absorption coefficients can be obtained with ligands composed of polyaromatic structures, but the electronic delocalization is accompanied by a bathochromic displacement of the absorption bands, which is beneficial to limit damage to biological material and to decrease the absorption of the biomaterials, ${ }^{[17]}$ but rapidly becomes incompatible with the matching of the lanthanide-centered energy levels, resulting in possible back energy transfer in the best cases ${ }^{[18]}$ and emission of the ligands in the worst. An alternative to overcome this limitation is to use multiple antennae with adequate energy levels around a single lanthanide cation, as is the case for most of the currently known efficient Ln labels that contain three ${ }^{[3]}$ or four ${ }^{[4]}$ antennae around the metal. Unfortunately, simple steric considerations immediately show the limits of this approach if one considers that an optimized energy transfer requires the direct coordination of the antennae to the Ln cations. Alternatively, the introduction of more than one Ln complex on a single scaffold can be envisaged.

Although this approach has been largely exemplified with organic compounds, far fewer polynuclear Ln complexes have been developed. ${ }^{[19-22]}$ It is well established that the accumulation of fluorescent compounds may lead to a loss of some of the fluorescence properties by self-quenching through homo-FRET (Förster resonance energy transfer) or formation of excimers or exciplexes, ${ }^{[23]}$ as stacking interactions become important for polyaromatic compounds. In the case of Ln-doped luminescent solids, the antenna effect can also be beneficial to increase the overall brightness, ${ }^{[24,25]}$ but the phenomenon of self-quenching was also observed when the concentration of the active emitting Ln cations becomes too high. ${ }^{[26]}$ The phenomenon was first ascribed to the presence of quenching impurities, which, after migration of the excitation energy through the solid, lead to non-radiative deactivation. However, by working with high purity compounds, Auzel $^{[27]}$ showed that the quenching centers could in fact be the active centers themselves, which form cluster-like pairs that enhance non-radiative multi-phonon assisted energy transfer. Controlling the energy migration pathways is thus of particular importance to improve some lanthanide luminescence properties such as upconversion phenomena, both in the solid state ${ }^{[28]}$ or at the molecular level. ${ }^{[29,30]}$

In previous works, ${ }^{[31,32]}$ it has been shown that the macrocyclic ligand $\mathrm{H}_{2} \mathbf{L}_{\mathbf{1}}$ (Scheme 1) forms eightcoordinate complexes with $\mathrm{Ln}$ ions both in the solid state and in solution. The presence of the methyl substituents in positions 1 and 7 of the cyclen moiety introduces a certain degree of steric hindrance on the picolinate pendants that prevents the coordination of water molecules. Furthermore, the Ln complexes of this 
ligand present rather high thermodynamic stability and are remarkably inert with respect to complex dissociation. ${ }^{[33]}$ In this work, a series of mono-, di-, and tritopic ligands $\left(\mathrm{H}_{2} \mathbf{L}_{1}\right.$ to $\mathrm{H}_{6} \mathbf{L}_{3}$, respectively, Scheme 1) were prepared to evaluate the influence of increasing nuclearity on the photophysical properties of the complexes of $\mathrm{Eu}^{3+}$ and $\mathrm{Tb}^{3+}$. The synthesis of the ligands and complexes are presented, together with their spectroscopic properties.

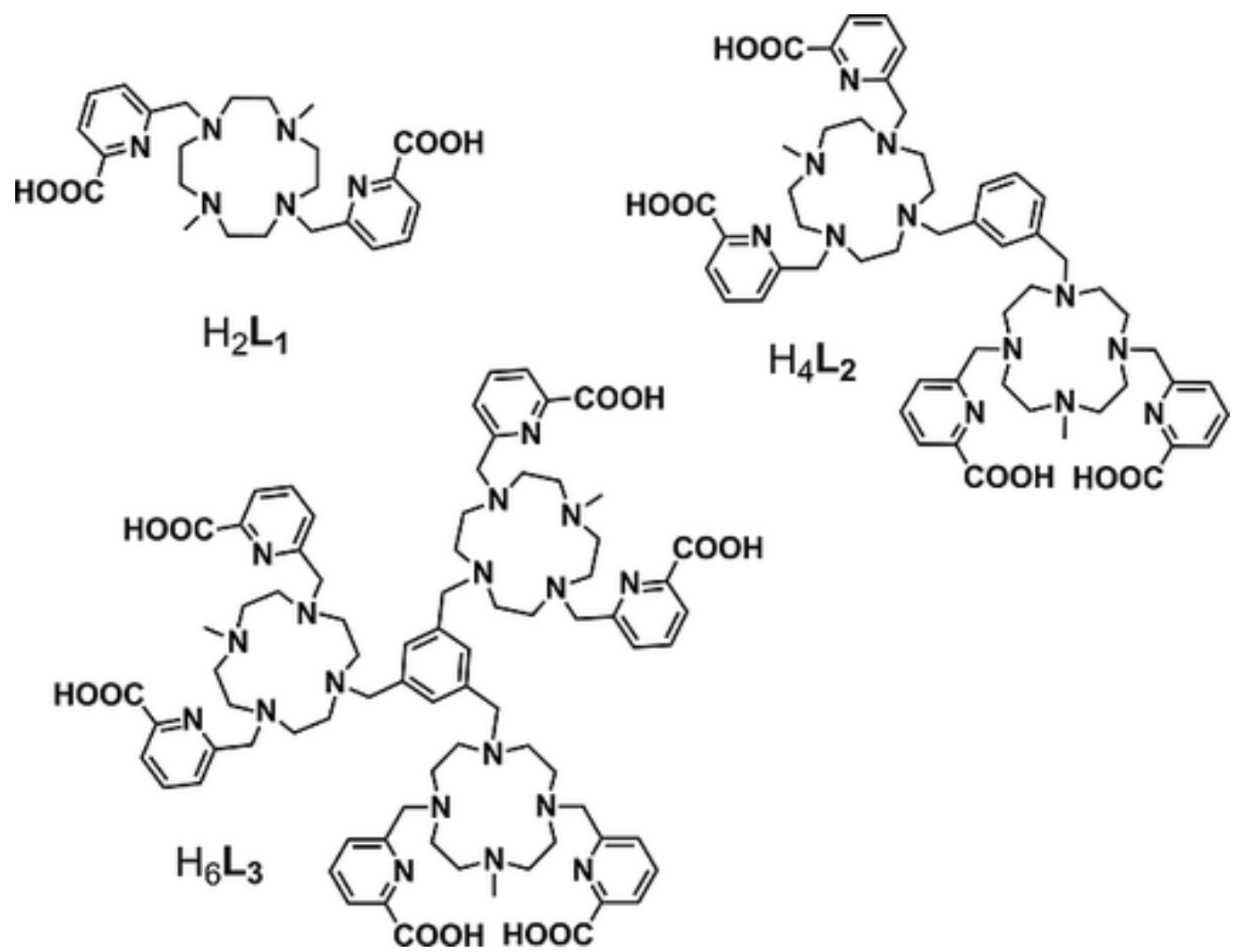

Scheme 1. Mono-, di-, and tritopic ligands $\left(\mathrm{H}_{2} \mathbf{L}_{1}, \mathrm{H}_{4} \mathbf{L}_{2}\right.$, and $\left.\mathrm{H}_{6} \mathbf{L}_{3}\right)$.

\section{Results and Discussion}

Synthesis of the Ligands and Metal Complexes

The synthesis of the ligands $\mathbf{L}_{\mathbf{1}}-\mathbf{L}_{\mathbf{3}}$ are depicted in Scheme 2 and Scheme 3. 1,7-Dipicolinic cylen precursor $\mathbf{1}$ was obtained according to literature procedures. ${ }^{[31]}$ Alkylation of $\mathbf{1}$ with methyl iodide afforded a mixture of the monomethylated (2) and dimethylated (3) cyclen precursors. Saponification of the methylpicolinate esters of $\mathbf{3}$ followed by acidification afforded $\mathrm{H}_{2} \mathbf{L}_{1}$ quantitatively, the synthesis of which has already been reported $\left[\mathrm{H}_{2} \mathrm{Me}-\mathrm{DODPA}=6,6^{\prime}\right.$-((4,10-dimethyl-1,4,7,10-tetraazacyclododecane-1,7diyl)bis(methylene))dipicolinic acid]. ${ }^{[31]} \mathrm{N}$-Alkylation of para-dibromomethylbenzene with 2yielded intermediate 4, which upon saponification, acidification, and purification afforded ligand $\mathrm{H}_{4} \mathbf{L}_{2}$ in $52 \%$ yield for the two steps.

The synthetic pathway used for the preparation of $\mathrm{H}_{6} \mathbf{L}_{3}$ started with the alkylation of 1,3,5tribromomethylbenzene $\mathbf{6}$ with the iodide salt of the methylated glyoxal protected cyclen $\mathbf{5}$, prepared according to literature procedures. ${ }^{[34]}$ The hexacationic salt that precipitated (named $7 \mathbf{a}$ in the Experimental Section) can be readily deprotected in quantitative yield by using pure hydrazine hydrate to afford compound 7. Alkylation of the secondary amine nitrogen atoms of the cyclen rings was achieved with the 
methyl ester of chloromethylpicolinic acid ${ }^{[35]}$ to give compound $\mathbf{8}$ in $87 \%$ yield. A final acidic hydrolysis of the methyl esters afforded the tritopic ligand $\mathrm{H}_{6} \mathbf{L}_{3}$ as its hydrochloride salt.

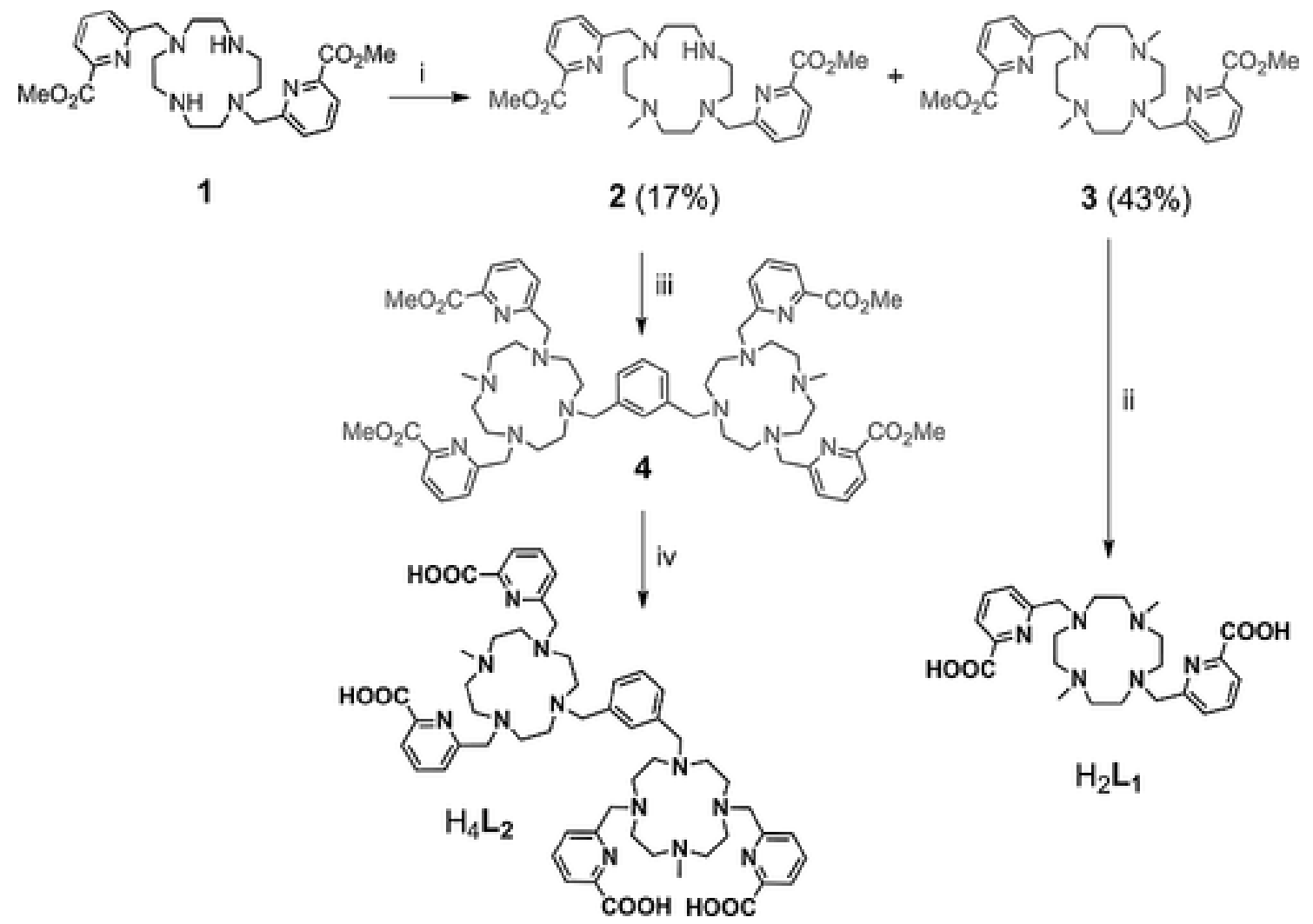

Scheme 2. Synthesis of ligands $\mathrm{H}_{2} \mathbf{L}_{1}$ and $\mathrm{H}_{4} \mathbf{L}_{2}$. Reagents and conditions: (i) $\mathrm{Na}_{2} \mathrm{CO}_{3}, \mathrm{CH}_{3} \mathrm{I}, \mathrm{CH}_{3} \mathrm{CN}, 50{ }^{\circ} \mathrm{C}$. (ii) $\mathrm{NaOH}$, $\mathrm{MeOH} / \mathrm{H}_{2} \mathrm{O}, 100{ }^{\circ} \mathrm{C}$ then $\mathrm{HCl}^{[31]}$ (iii) 1,3-Dibromomethylbenzene, $\mathrm{CH}_{3} \mathrm{CN}$, reflux, then (iv) $\mathrm{NaOH}, \mathrm{MeOH} / \mathrm{H}_{2} \mathrm{O}, 100$ ${ }^{\circ} \mathrm{C}$, then $\mathrm{HCl} ; 52 \%$ for the two steps.

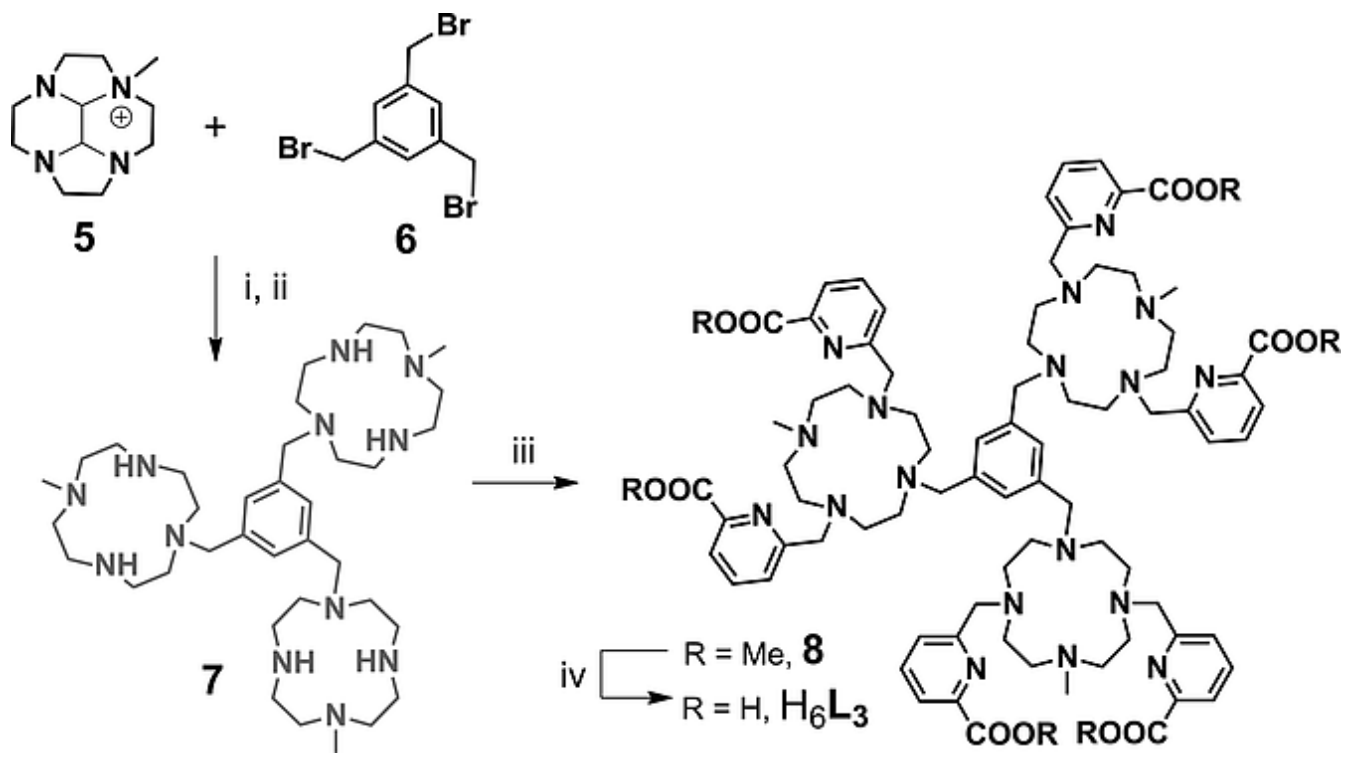

Scheme 3. Synthesis of ligand $\mathrm{H}_{6} \mathbf{L}_{3}$. Reagents and conditions: (i) $\mathrm{CH}_{3} \mathrm{CN}, 40{ }^{\circ} \mathrm{C}, 92 \%$. (ii) $\mathrm{H}_{2} \mathrm{NNH}_{2} \cdot \mathrm{H}_{2} \mathrm{O}$, reflux, quant. (iii) $\mathrm{K}_{2} \mathrm{CO}_{3}, \mathrm{CH}_{3} \mathrm{CN}$, methyl 6-(chloromethyl)picolinate, $40{ }^{\circ} \mathrm{C}, 87 \%$. (iv) $\mathrm{HCl}$, reflux, quant. 
$\mathrm{Eu}^{3+}$ and $\mathrm{Tb}^{3+}$ complexes of the three ligands were obtained by mixing small excesses of the corresponding hydrated chloride lanthanide salts with the ligands in hot butanol in the presence of diisopropylethylamine as a base for a few days. It has been shown that the complexation kinetics of lanthanide complexes of some cross-bridged cyclam picolinate ligands are very slow. ${ }^{[36]}$ In the case of the complexes of $\mathrm{H}_{4} \mathbf{L}_{\mathbf{2}}$ and $\mathrm{H}_{6} \mathbf{L}_{\mathbf{3}}$, full complexation required heating the reaction mixtures for very long times to complete the coordination of the cations in all the cyclen sites, as demonstrated by the ES/MS spectra of the complexes (Figures S1, S3, S5, and S7, in the Supporting Information).

\section{$\underline{\text { Spectroscopic Properties of the Complexes }}$}

The main spectroscopic properties measured for the $\left[\operatorname{Ln}_{x} \mathbf{L}_{x}\right] \mathrm{Cl}_{x}$ complexes $(x=1$ to $3, \mathrm{Ln}=\mathrm{Eu}$ or $\mathrm{Tb}$ ) are presented in Table 1.

Table 1. Main spectroscopic properties of the Eu3+ and Tb3+ complexes of $\mathbf{L}_{\mathbf{1}}-\mathbf{L}_{\mathbf{3}}{ }^{[\mathrm{a}]}$

\begin{tabular}{llllllll}
\hline & $\begin{array}{l}\text { Absorption } \\
\lambda_{\max } / \mathrm{nm}\end{array}$ & $\varepsilon / \mathrm{M}^{-1} \mathrm{~cm}^{-1}$ & $\begin{array}{l}\text { Emission } \\
\tau_{\mathrm{H} 2 \mathrm{O}} / \mathrm{ms}\end{array}$ & $\tau_{\mathrm{D} 2 \mathrm{O}} / \mathrm{ms}$ & $\phi^{[\mathrm{b}]}$ & $q^{[\mathrm{c}]}$ & $B=\phi \cdot \varepsilon / \mathrm{M}^{-1} \mathrm{~cm}^{-1}$ \\
\hline$\left[\mathrm{Eu} \mathbf{L}_{1}\right]^{+}$ & 274 & 9300 & 0.96 & 1.19 & 0.10 & 0 & 930 \\
{$\left[\mathrm{Eu}_{2} \mathbf{L}_{2}\right]^{2+}$} & 274 & 21300 & 0.93 & 1.25 & 0.10 & 0 & 2130 \\
{$\left[\mathrm{Eu}_{3} \mathbf{L}_{3}\right]^{3+}$} & 274 & 35900 & 0.92 & 1.16 & 0.08 & 0 & 2870 \\
{$\left[\mathrm{~Tb}_{\mathbf{1}}\right]^{+}$} & 274 & 11950 & 2.55 & 2.69 & 0.58 & 0 & 6930 \\
{$\left[\mathrm{~Tb}_{2} \mathbf{L}_{2}\right]^{2+}$} & 274 & 21100 & 2.48 & 2.50 & 0.53 & 0 & 11180 \\
{$\left[\mathrm{~Tb}_{3} \mathbf{L}_{3}\right]^{3+}$} & 274 & 31500 & 2.07 & 2.17 & 0.44 & 0 & 13860 \\
\hline
\end{tabular}

[a] Estimated errors: $\pm 1 \mathrm{~nm}$ on $\lambda_{\max }, \pm 20 \%$ on $\varepsilon, \pm 10 \%$ on $\tau, \pm 15 \%$ on $\phi$, and \pm 0.2 on $q$. [b] In Tris/HCl $0.01 \mathrm{~m}, \mathrm{pH}$ 6.9. [c] Calculated according to ref. 10.

The UV/Vis absorption spectra of the complexes are very similar in shape (Figure 1, and Figures S5 and S6). They all display a major absorption band with a maximum at $274 \mathrm{~nm}$, which can be attributed to $\pi \rightarrow \pi^{*}$ transitions centered on the pyridyl moieties, as largely exemplified in the literature for similar complexes. ${ }^{[37,38]}$ One can also notice the presence of a second peak at $281 \mathrm{~nm}$ and a shoulder at higher energy (approximately $267 \mathrm{~nm}$ ), pointing to a vibronic progression of approximately $940 \mathrm{~cm}^{-1}$. This may be related to medium absorption bands observed at 964,950 , and $949 \mathrm{~cm}^{-1}$, respectively, in the infrared spectra of the mono-, di-, and trinuclear complexes, which may be associated with the $v_{5}$ out-of-plane $\mathrm{CH}$ vibration band of the pyridyl moieties, as observed at $942 \mathrm{~cm}^{-1}$ in pure pyridine, ${ }^{[39]}$ and which is slightly shifted in pyridinium complexes of $\mathrm{Mn}, \mathrm{Cu}$, or $\mathrm{Zn} .{ }^{[40]}$ The molar absorption coefficients of the complexes display an almost linear increase for the mono- to trinuclear complexes (see inset of Figure 1), showing the absorption to be an extensive parameter, as expected in the absence of electronic communication between the different chromophores. From the slopes of the linear regression analysis of the data, one obtains an absorption coefficient of $11000 \pm 400 \mathrm{~m}^{-1} \mathrm{~cm}^{-1}$ for two picolinate units.

Figure 2 presents the metal-centered emission spectra of the Eu complexes upon ligand excitation at $274 \mathrm{~nm}$, normalized to the concentrations of the complexes. The emission spectra display the typical emission bands arising from the ${ }^{5} \mathrm{D}_{0} \rightarrow{ }^{7} \mathrm{~F}_{J}$ transitions centered on the europium with $J=0(578 \mathrm{~nm}), J=1(580-600 \mathrm{~nm}), J=$ $2(600-630 \mathrm{~nm}), J=3(645-660 \mathrm{~nm})$, and $J=4(670-720 \mathrm{~nm})$. The relative intensities of the ${ }^{7} \mathrm{~F}_{2} /{ }^{7} \mathrm{~F}_{1}$ transitions point to a very low symmetry around the Eu cations. Interestingly, the shapes of all three complexes are very similar, pointing to similar coordination environments for all the sites in the complexes. The ${ }^{5} \mathrm{D}_{0} \rightarrow{ }^{7} \mathrm{~F}_{1}$ transition displays one band at $588.0 \mathrm{~nm}$ and two components at 593.2 and 595.4 
$\mathrm{nm}$, split by only $62 \pm 10 \mathrm{~cm}^{-1}$, in agreement with the expected $C_{2}$ local symmetry around the Eu cations. ${ }^{[41]}$ The metal-centered excitation spectra $\left(\lambda_{\mathrm{em}}=610 \mathrm{~nm}\right)$ can be found in Figure S13. The Eu-centered luminescence decay could all be perfectly fitted with mono-exponential lifetimes, which are almost the same for the three complexes within experimental error. On the basis of the excited lifetimes in $\mathrm{H}_{2} \mathrm{O}$ and $\mathrm{D}_{2} \mathrm{O}$, the hydration numbers could be determined, ${ }^{[10]}$ pointing to the absence of water molecules in the first coordination sphere of the Eu cations. By using the methodology developed by Werts and co-workers, ${ }^{[42]}$ we calculated that the europium-centered luminescence quantum yield is 0.20 for the three complexes with a sensitization efficiency of $0.51,0.50$, and 0.40 , respectively, for the mono-, di-, and trinuclear complexes (see details in Annex 1 in the Supporting Information).

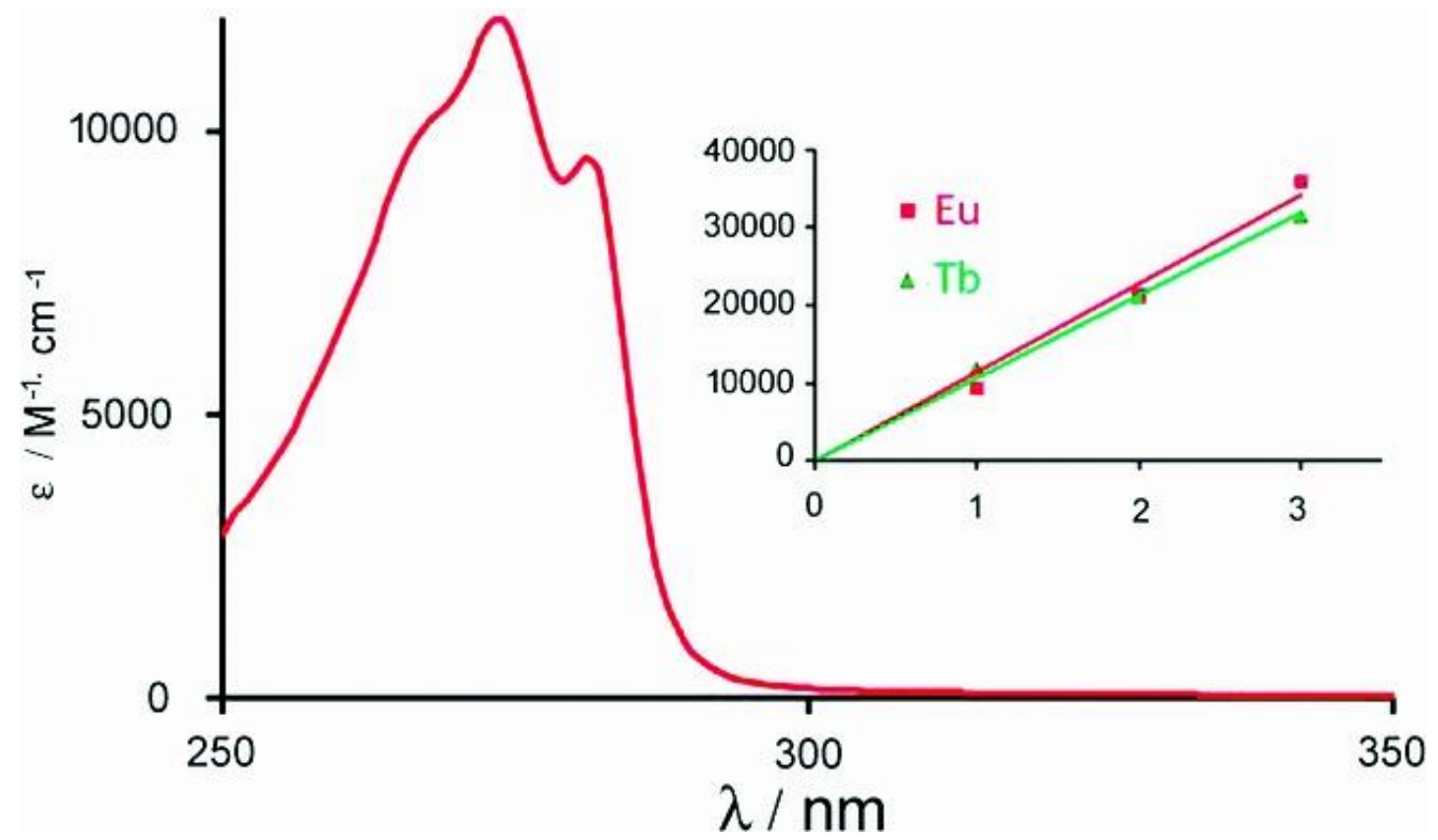

Figure 1. UV/Vis absorption spectrum of $\left[\mathrm{TbL}_{1}\right] \mathrm{Cl}$ in aqueous Tris/ $\mathrm{HCl}\left(0.01 \mathrm{~m}, \mathrm{pH} 6.9, c=1.91 \times 10^{-4} \mathrm{~m}, 25^{\circ} \mathrm{C}\right)$. Inset: evolution of the molar absorption coefficients at $274 \mathrm{~nm}$ for the $\mathrm{Eu}^{3+}$ (red) and $\mathrm{Tb}^{3+}$ (green) complexes with the increase of the number of Ln cations per ligand (straight lines are the corresponding linear regressions).

Finally, the luminescence quantum yields were determined to be, respectively, 0.10, 0.10, and 0.08, which are very similar to reported data for Eu-based picolinate complexes that lack inner sphere water molecules. ${ }^{[43,44]}$ Although the value obtained for the trinuclear complex is a little bit smaller than for the other two, the observed difference cannot be considered as significant regarding the $15 \%$ absolute error on these determinations.

Figure 3 presents the emission spectra of the Tb complexes obtained upon ligand excitation. The spectra display the typical Tb-centered emission pattern, with ${ }^{5} \mathrm{D}_{4} \rightarrow{ }^{7} \mathrm{~F}_{J}$ transitions, with $J=6$ (491 nm), $J=5$ (545 $\mathrm{nm}), J=4(585 \mathrm{~nm}), J=3(620 \mathrm{~nm})$, and the weak $J=2$ to $0(640-690 \mathrm{~nm})$ bands. As for Eu, the shapes of the spectra are very similar, pointing to similar coordination environments for all the $\mathrm{Tb}$ atoms in the different complexes and within a complex for the polynuclear species. The metal-centered excitation spectra $\left(\lambda_{\mathrm{em}}=545 \mathrm{~nm}\right)$ can be found in Figure S12 in the Supporting Information. In contrast to Eu, a small decrease of the luminescence quantum yield could be observed from $\mathbf{L}_{\mathbf{1}}$ to $\mathbf{L}_{\mathbf{3}}$. Although this drop is rather modest from $\mathrm{Tb}_{\mathbf{1}}$ to $\mathrm{Tb}_{2} \mathbf{L}_{2}(0.58$ to 0.53$)$, it becomes more significant for $\mathrm{Tb}_{3} \mathbf{L}_{\mathbf{3}}(0.44)$, but still not significant relative to the uncertainties of the error. Moreover, HPLC analysis of the trinuclear complex (Figure S8) revealed the presence of small impurities, which may explain the drop in luminescence efficiency. 


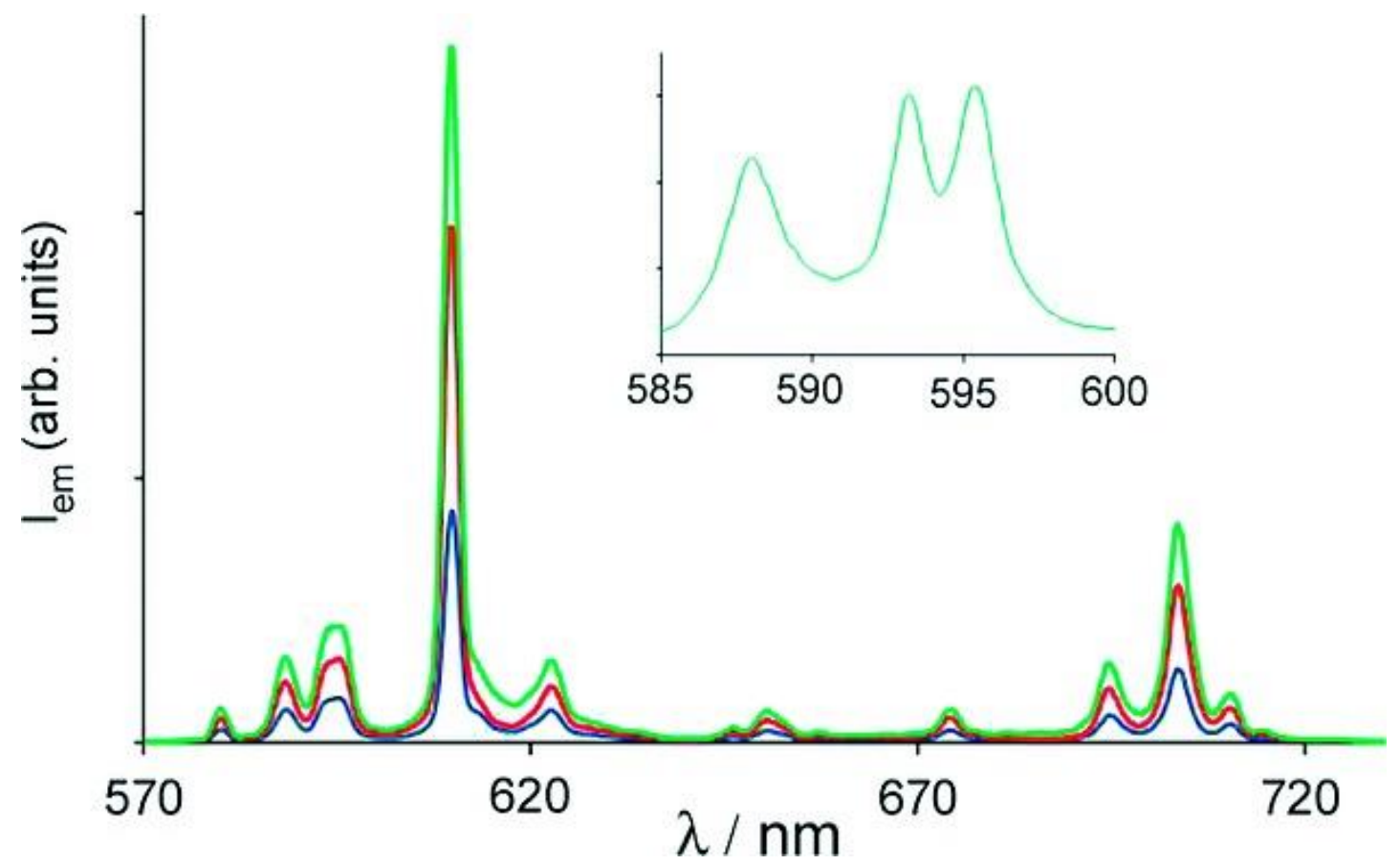

Figure 2. Metal-centered emission of the Eu complexes with ligands $\mathbf{L}_{\mathbf{1}}$ (blue, $\left.c=5.0 \times 10^{-6} \mathrm{~m}\right), \mathbf{L}_{\mathbf{2}}\left(\mathrm{red}, c^{=}=1.4 \times 10^{-}\right.$ ${ }^{6} \mathrm{~m}$ ), and $\mathbf{L}_{\mathbf{3}}$ (green, $c=2.3 \times 10^{-6} \mathrm{~m}$ ) in aqueous Tris $/ \mathrm{HCl}\left(0.01 \mathrm{~m}, \mathrm{pH} 6.9,25^{\circ} \mathrm{C}\right)$ normalized to the concentrations $\left(\lambda_{\text {exc }}=274 \mathrm{~nm}\right)$. Inset: enlargement of the ${ }^{5} \mathrm{D}_{0} \rightarrow{ }^{7} \mathrm{~F}_{1}$ transitions at a $0.2 \mathrm{~nm}$ resolution.

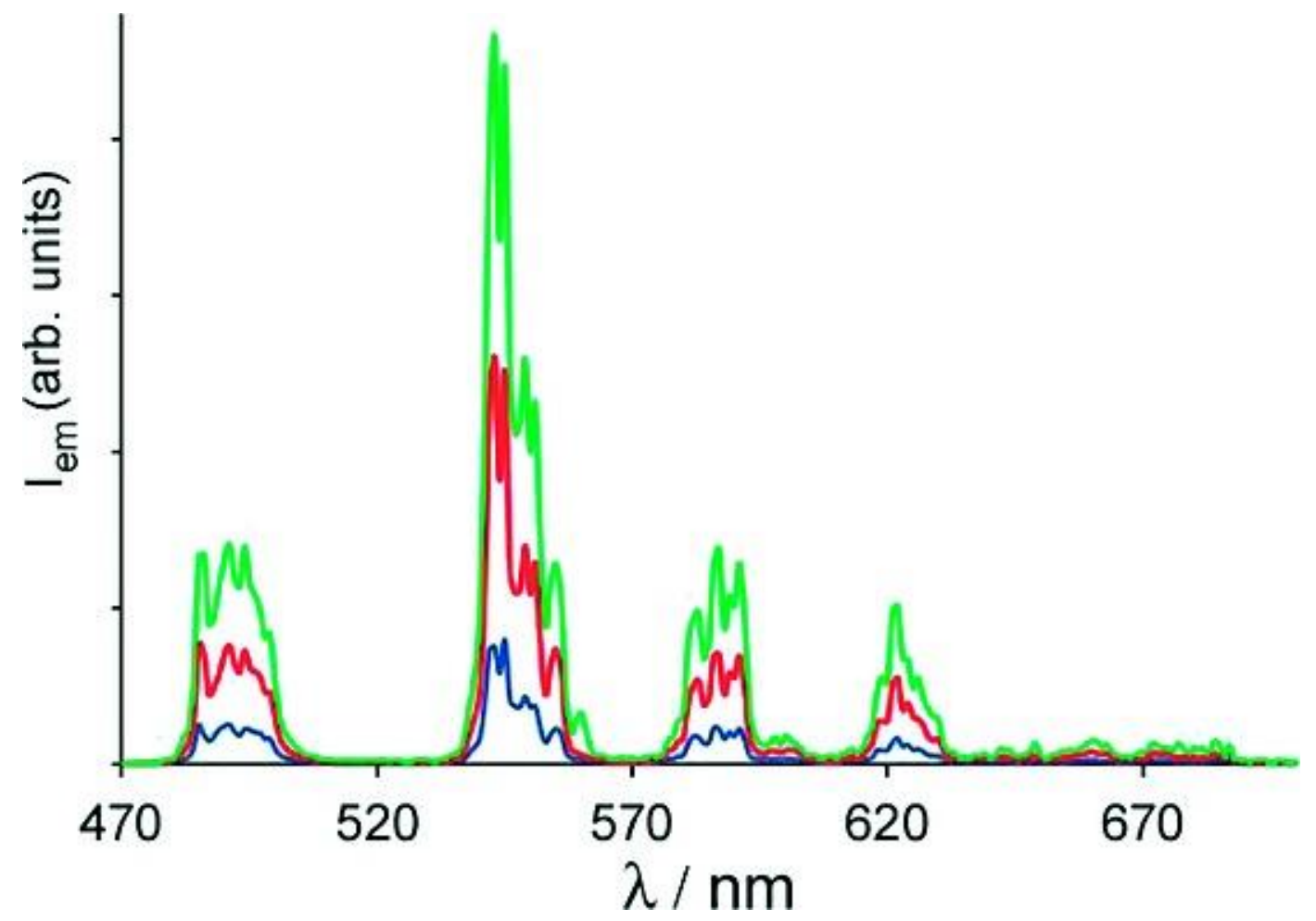

Figure 3. Metal-centered emission of the Tb complexes with ligands $\mathbf{L}_{\mathbf{1}}$ (blue, $\left.c=1.6 \times 10^{-6} \mathrm{~m}\right), \mathbf{L}_{\mathbf{2}}\left(\mathrm{red}, c^{=}=2.5 \times 10^{-}\right.$ ${ }^{6} \mathrm{~m}$ ), and $\mathbf{L}_{3}$ (green, $c=4.0 \times 10^{-6} \mathrm{~m}$ ) in aqueous Tris $/ \mathrm{HCl}\left(0.01 \mathrm{~m}, \mathrm{pH} 6.9,25^{\circ} \mathrm{C}\right)$ normalized to the concentrations $\left(\lambda_{\mathrm{exc}}=274 \mathrm{~nm}\right)$. 
For all complexes, the calculation of the hydration numbers revealed perfect protection of the Tb cations with no coordinated water molecules in the first spheres. All the excited-state lifetimes could be fitted with mono-exponential decays, and here again, one could notice a decrease of the excited-state lifetime within the series. In that case, the drop observed from $\operatorname{Tb}_{\mathbf{1}}(2.55 \mathrm{~ms})$, to $\mathrm{Tb}_{2} \mathbf{L}_{\mathbf{2}}(2.48 \mathrm{~ms})$, and to $\mathrm{Tb}_{3} \mathbf{L}_{\mathbf{3}}(2.07 \mathrm{~ms})$ became significant and could not be explained by the uncertainties on the measurement $(10 \%)$. The Tbcentered luminescence lifetimes were also measured upon direct excitation into the ${ }^{7} \mathrm{~F}_{6} \rightarrow{ }^{5} \mathrm{D}_{4}$ absorption band of $\mathrm{Tb}$ at $485 \mathrm{~nm}$. The decay at $545 \mathrm{~nm}$ could also be perfectly fitted with mono-exponential functions, confirming the decrease to 2.46 and $2.06 \mathrm{~ms}$ for the dinuclear and trinuclear Tb complexes, respectively. As a global consequence, the brightness of the trinuclear complex displayed only a small increase compared with its dinuclear analog. This observed phenomenon was quite puzzling and could only be explained by a particular behavior of the trinuclear species. Although it has been shown that intramolecular energy transfer within lanthanide cations and in particular europium are limited to short distances, ${ }^{[45]}$ the possibility of intramolecular Ln to Ln energy transfer previously observed in a homobimetallic europium complex with two distinct environments ${ }^{[46]}$ was a putative explanation. However, the energy migration within equivalent sites in a complex should not result in non-radiative de-excitations, the loss occurring from one site to the others being compensated by the energy migrations in the reverse way.

Energy transfer mechanisms are strongly related to the distances between energy donors and acceptors. To get more information about the molecular structures of the complexes, we turned our attention to the theoretical modeling of the dinuclear and trinuclear complexes.

\section{Theoretical Modeling of the Complexes}

Figure 4 represents the molecular geometries of the $\left[\mathrm{Eu}_{2} \mathbf{L}_{2}\right]^{2+}$ and $\left[\mathrm{Eu}_{3} \mathbf{L}_{3}\right]^{3+}$ complexes calculated at the HF/LCECP/3-21G level. The solid-state and solution structures of the $\left[\mathbf{L n} \mathbf{L}_{1}\right]^{+}$complexes have been reported in previous works. ${ }^{[31,32]}$ Herein, theoretical calculations were carried out to estimate the intramolecular Ln $\cdots$ Ln distances in the binuclear and trinuclear $\left[\operatorname{Ln}_{2} \mathbf{L}_{2}\right]^{2+}$ and $\left[\operatorname{Ln}_{3} \mathbf{L}_{3}\right]^{3+}$ entities. Whatever the complexes and the sites within a complex, the Eu coordination environments are very similar, the Eu atoms being coordinated by the four nitrogen atoms of the cyclen ring, the two pyridine nitrogen atoms, and the two carboxylate oxygen atoms. The Eu cations are placed above the mean plane of the cyclen rings and the picolinate arms are wrapped around the cations, as observed in the X-ray crystal structure of $\left[\mathrm{EuL}_{\mathbf{1}}\right]^{+} .{ }^{[32]}$
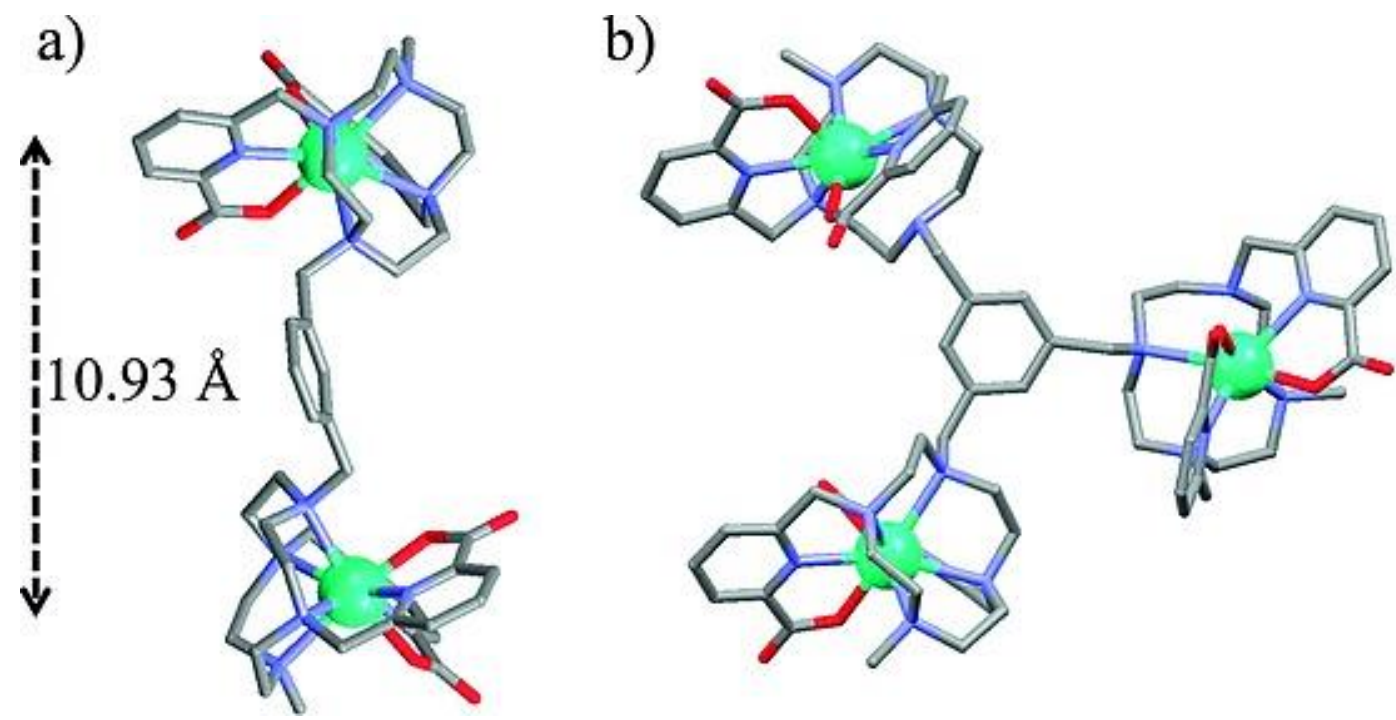

Figure 4. Molecular geometries of the $\left[\mathrm{Eu}_{2} \mathbf{L}_{2}\right]^{2+}$ (a) and $\left[\mathrm{Eu}_{3} \mathbf{L}_{3}\right]^{3+}$ (b) complexes calculated at the HF/LCECP/3-21G level. 
The geometry of the $\left[\mathrm{Eu}_{2} \mathbf{L}_{2}\right]^{2+}$ complex provides average distances between the metal ion and the nitrogen atoms of the macrocycle of 2.65-2.67 $\AA$. These distances are only approximately $0.06-0.08 \AA$ longer than those observed in the X-ray crystal structure of the $\left[\mathrm{Eu}_{\mathbf{1}}\right]^{+}$complex $(\approx 2.59 \AA)$. The calculated Eu-O distances $(2.33 \AA)$ present excellent agreement with those observed in the solid state for $\left[\mathrm{Eu}_{\mathbf{1}}\right]^{+}(2.325$ $\AA$ ). ${ }^{[32]}$

In the dinuclear complex, the two coordinating sites are pushed away one from the other, probably owing to electrostatic reasons, the conformation around the ortho-benzyl spacer being trans. In this conformation, the distance between the Eu centers amounts to $10.93 \AA$. In the trinuclear complex, the three Eu atoms form a quasi-isosceles triangle, with two short Eu-Eu distances of 10.49 and $10.53 \AA$ and a long one of $11.74 \AA$. The two atoms located at the longest distance are situated on one side of the plane formed by the central benzene ring, the third Eu atom being on the other side. On average, the Eu-Eu distance is $10.92 \AA$, which is very similar to that observed in the model of $\left[\mathrm{Eu}_{2} \mathbf{L}_{2}\right]^{2+}$.

\section{Conclusions}

The spectroscopic properties determined for these families of mono- to trinuclear complexes of $\mathrm{Eu}^{3+}$ and $\mathrm{Tb}^{3+}$ confirmed that spectroscopic properties such as absorption and brightness are extensive parameters. Only in the case of the polynuclear complexes of $\mathrm{Tb}$, could we noticed a small drop in the luminescence characteristics such as the luminescence quantum yield or the excited-state lifetimes. If the decrease of the luminescence quantum yield may find its origins in the presence of small impurities for the trinuclear complex, it hardly explains the non-negligible decrease of the excited-state lifetimes, especially as those were obtained by excitation through the ligand or directly in the Tb transitions. Unfortunately, the origin of this phenomenon is still unclear in this case.

The design of polynuclear complexes as an alternative to increase the brightness of lanthanide labels nevertheless deserves a certain interest to improve the luminescence properties of Ln biomarkers.

\section{Experimental Section}

\section{Chemicals and Starting Materials}

8a-Methyldecahydro-2H-2a,4a,6a,8a-tetraazacyclopenta-[fg]acenaphthylen-8a-ium iodide $(\mathbf{5}),{ }^{[34]}$ methyl 6(chloromethyl)picolinate, ${ }^{[35]}$ ligand $\mathrm{H}_{2} \mathbf{L}_{\mathbf{1}}$ and its $\mathrm{Eu}$ and $\mathrm{Tb}$ complexes ${ }^{[31]}$ were prepared according to the published procedures. All other chemicals were purchased from commercial sources and used without further purification, unless otherwise stated. Column chromatographic purifications were performed on silica (60-200 $\mu \mathrm{m}$, Merck). $\mathrm{K}_{2} \mathrm{CO}_{3}$ was flash dried under vacuum prior to use. ${ }^{1} \mathrm{H}$ and ${ }^{13} \mathrm{C}$ NMR experiments were performed with Bruker Avance 300 and Avance 400 spectrometers working at 300 and $400 \mathrm{MHz}$, respectively, for ${ }^{1} \mathrm{H}$. Chemical shifts are given in parts per million relative to residual protiated solvents. ${ }^{[47]}$ HPLC-UV analysis of the complexes was performed with a Thermo Fischer Scientific Ultimate 300 system equipped with an Interchim Phenyl US5PHC4 column $(250 \mathrm{~mm} \times 4.6 \mathrm{~mm}, \phi=5 \mu \mathrm{m})$ by using solvent mixtures of $\mathrm{H}_{2} \mathrm{O}+0.1 \%$ formic acid (solvent $\mathrm{A}$ ) and acetonitrile $+0.1 \%$ formic acid (solvent $\mathrm{B}$ ). The profile gradient was 5, 5, 15, 22, 5, and 5\% solvent B in solvent A changing after $0,5,15,22,23$, and $35 \mathrm{~min}$, respectively, at a flow rate of $1 \mathrm{~mL} \mathrm{~min}^{-1}$. The detection was performed at $274 \mathrm{~nm}$. UPLC-Q-TOF analysis of the $\mathrm{Tb}$ trinuclear complex was performed with a Acquity Waters apparatus with a phenyl column $(100 \mathrm{~mm} \times 2.1 \mathrm{~mm}, \phi=5 \mu \mathrm{m})$ with the same eluents and gradients. HPLC chromatograms of the dinuclear and trinuclear complexes can be found in the Supporting Information. 
A mixture of $1(896 \mathrm{mg}, 1.9 \mathrm{mmol})$ and $\mathrm{K}_{2} \mathrm{CO}_{3}(578 \mathrm{mg}, 4.19 \mathrm{mmol})$ was heated to $60{ }^{\circ} \mathrm{C}$ for $10 \mathrm{~min}$, and $\mathrm{CH}_{3} \mathrm{I}$ (324 mg, $2.28 \mathrm{mmol}$ ) in $150 \mathrm{~mL}$ of $\mathrm{CH}_{3} \mathrm{CN}$ was added. The mixture was heated at $60{ }^{\circ} \mathrm{C}$ overnight and concentrated to dryness. The residue was dissolved in $\mathrm{CH}_{2} \mathrm{Cl}_{2}$ and washed three times with water. The organic phase was dried with $\mathrm{Na}_{2} \mathrm{SO}_{4}$, filtered, and the solvents evaporated to dryness. The residue was purified by column chromatography $\left(\mathrm{Al}_{2} \mathrm{O}_{3}\right.$ act. III, $\left.\mathrm{CH}_{2} \mathrm{Cl}_{2} / \mathrm{MeOH}, 97: 3\right)$ to yield compound 2 (152 $\mathrm{mg}$, $17 \%)$ as a yellow oil and compound $3^{[31]}(244 \mathrm{mg}, 43 \%) .{ }^{1} \mathrm{H}$ NMR $\left(\mathrm{CDCl}_{3}, 400 \mathrm{MHz}, 25{ }^{\circ} \mathrm{C}\right): \delta=7.99$ $(\mathrm{d}, J=7.6 \mathrm{~Hz}, 2 \mathrm{H}), 7.78$ (t, $J=7.7 \mathrm{~Hz}, 2 \mathrm{H}), 7.61(\mathrm{~d}, J=7.8 \mathrm{~Hz}, 2 \mathrm{H}), 4.08(\mathrm{~s}, 4 \mathrm{H}), 3.96(\mathrm{~s}, 6 \mathrm{H}), 3.20-2.38$ $(\mathrm{m}, 17 \mathrm{H}), 2.05(\mathrm{~s}, 3 \mathrm{H}) \mathrm{ppm} .{ }^{13} \mathrm{C} \mathrm{NMR}\left(\mathrm{CDCl}_{3}, 100 \mathrm{MHz}, 25{ }^{\circ} \mathrm{C}\right): \delta=165.59,159.34,147.28,137.63$, 127.02, 123.91, 62.19, 56.51, 53.49, 52.88, 51.30, 49.93, $47.33 \mathrm{ppm}$. ESI ${ }^{+} / \mathrm{MS}\left(\mathrm{CH}_{2} \mathrm{Cl}_{2}\right): \mathrm{m} / z$ calcd. for $[M+$ $2 \mathrm{H}]^{2+}\left(\mathrm{C}_{25} \mathrm{H}_{38} \mathrm{~N}_{6} \mathrm{O}_{4}\right): 243.15$, found $243.15(100 \%)$; calcd. for $[M+\mathrm{H}]^{+}\left(\mathrm{C}_{25} \mathrm{H}_{37} \mathrm{~N}_{6} \mathrm{O}_{4}\right): 485.29$, found 485.28 .

\section{Ligand $\mathrm{H}_{4} \underline{L_{2}}$}

A mixture of $2(152 \mathrm{mg}, 0.31 \mathrm{mmol})$ and $\mathrm{Na}_{2} \mathrm{CO}_{3}(50 \mathrm{mg}, 0.47 \mathrm{mmol})$ in $10 \mathrm{~mL}$ of $\mathrm{CH}_{3} \mathrm{CN}$ was heated to reflux and 1,3-dibromomethylbenzene ( $38 \mathrm{mg}, 0.14 \mathrm{mmol}$ ) dissolved in $2 \mathrm{~mL}$ of $\mathrm{CH}_{3} \mathrm{CN}$ was added. The solution was heated to reflux for $76 \mathrm{~h}$, cooled to room temperature, and the solvents evaporated to dryness. The residue was dissolved in $\mathrm{CH}_{2} \mathrm{Cl}_{2}$ and the organic phase was washed twice with water and twice with brine, dried with $\mathrm{Na}_{2} \mathrm{SO}_{4}$, and the solvents evaporated to dryness. The crude product was dissolved in the minimum amount of $\mathrm{CH}_{2} \mathrm{Cl}_{2}$ and precipitated with AcOEt. The yellow precipitate was collected by centrifugation and dissolved in $\mathrm{MeOH}(2 \mathrm{~mL}) . \mathrm{NaOH}(60 \mathrm{mg})$ in $\mathrm{D}_{2} \mathrm{O}(1 \mathrm{~mL})$ was added and the mixture was heated at reflux overnight, then evaporated to dryness, dissolved in a minimum of water, acidified to $\mathrm{pH}$ 2 with $1 \mathrm{~m}$ aqueous $\mathrm{HCl}$, and the solvents evaporated to dryness. The residue was purified by using $\mathrm{C} 18$ reverse-phase chromatography with a gradient of $\left[\mathrm{CH}_{3} \mathrm{CN}+0.1\right.$ trifluoroacetic acid (TFA) $] /\left(\mathrm{H}_{2} \mathrm{O}+0.1 \%\right.$ TFA) from 5:95 to 100:0 in $45 \mathrm{~min}$, affording $\mathrm{H}_{4} \mathbf{L}_{2}$ as a yellowish solid (75 mg, 52\%). ${ }^{1} \mathrm{H}$ NMR $\left(\mathrm{D}_{2} \mathrm{O}, 400\right.$ MHz, $25^{\circ} \mathrm{C}$ ): $\delta=7.90-7.83(\mathrm{~m}, 8 \mathrm{H}), 7.48$ (d, $\left.J=7.5 \mathrm{~Hz}, 4 \mathrm{H}\right), 7.08$ (s, $\left.1 \mathrm{H}\right), 6.68$ (br. s, $2 \mathrm{H}$ ), 6.13 (br. m, 1 $\mathrm{H}), 4.16(\mathrm{~s}, 4 \mathrm{H}), 3.86\left(\mathrm{AB}\right.$ spin system, $\left.\delta_{\mathrm{A}}=3.92, \delta_{\mathrm{B}}=3.77, J_{\mathrm{AB}}=16.5 \mathrm{~Hz}, 8 \mathrm{H}\right), 3.43-2.83(\mathrm{~m}, 32 \mathrm{H}), 2.65$ (s, $6 \mathrm{H}) \mathrm{ppm} .{ }^{13} \mathrm{C}$ NMR $\left(\mathrm{D}_{2} \mathrm{O}, 100 \mathrm{MHz}, 25{ }^{\circ} \mathrm{C}\right): \delta=166.4,157.3,145.9,139.4,134.7,131.9,129.2,129.1$, 128.1, 124.9, 56.4, 55.9, 53.4, 49.6, 48.5, 48.3, $43.4 \mathrm{ppm}$. ESI $/ \mathrm{MS}\left(\mathrm{H}_{2} \mathrm{O}\right): \mathrm{m} / z$ calcd. for $[M+$ $2 \mathrm{H}]^{2+}\left(\mathrm{C}_{54} \mathrm{H}_{72} \mathrm{~N}_{12} \mathrm{O}_{8}\right): 508.28$, found 508.28 (100\%); calcd. for $[M+\mathrm{H}]^{+}\left(\mathrm{C}_{54} \mathrm{H}_{71} \mathrm{~N}_{12} \mathrm{O}_{8}\right): 1015.55$, found 1015.55 (30 \%). $\mathrm{C}_{54} \mathrm{H}_{70} \mathrm{~N}_{12} \mathrm{O}_{8} \cdot 5 \mathrm{CF}_{3} \mathrm{CO}_{2} \mathrm{H} \cdot 4 \mathrm{H}_{2} \mathrm{O}$ (1657.4): calcd. C 46.38, $\mathrm{H}$ 5.05, $\mathrm{N}$ 10.14; found $\mathrm{C} 46.15, \mathrm{H}$ $5.43, \mathrm{~N} 9.89$.

$\underline{4 a, 4 a^{\prime}, 4 a^{\prime \prime}-[B e n z e n e-1,3,5-t r i y l t r i s(m e t h y l e n e)] t r i s(8 a-m e t h y l d o d e c a h y d r o-2 a, 4 a, 6 a, 8 a-~}$ tetraazacyclopenta[fg]acenaphthylene-4a,8a-diium) Tribromide Triiodide (7a)

Compound $5(1.30 \mathrm{~g}, \quad 3.88 \mathrm{mmol})$ was dissolved in dry acetonitrile $(25 \mathrm{~mL})$ and 1,3,5tris(bromomethyl)benzene $6(0.433 \mathrm{~g}, 1.21 \mathrm{mmol})$ was added. A white precipitate was formed after a few minutes. The mixture was stirred and heated at $40{ }^{\circ} \mathrm{C}$ for $24 \mathrm{~h}$, and then the white solid was isolated by

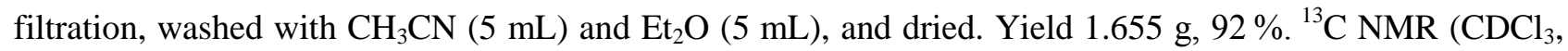
$\left.75 \mathrm{MHz}, 25^{\circ} \mathrm{C}\right): \delta=136.7,127.7,58.4,53.0,50.6,50.5,44.2,43.0$ ppm. $\mathrm{C}_{42} \mathrm{H}_{84} \mathrm{Br}_{3} \mathrm{I}_{3} \mathrm{~N}_{12} \mathrm{O}_{6} \cdot 7 \mathrm{H}_{2} \mathrm{O}(1599.7)$ : calcd. C 33.82, H 5.81, N 11.27; found C 33.83, H 5.17, N 10.98. IR (ATR): $\tilde{v}=2952$ and 2807 (C-H), 1723 $(\mathrm{C}=\mathrm{O}), 1590$ and $1512(\mathrm{C}=\mathrm{N}$ and $\mathrm{C}=\mathrm{C}) \mathrm{cm}^{-1}$.

\section{1,3,5-Tris[(7-methyl-1,4,7,10-tetraazacyclododecan-1-yl)methyl]benzene (7)}

Compound $7 \mathbf{a} \cdot 7 \mathrm{H}_{2} \mathrm{O}(1.45 \mathrm{~g}, 0.97 \mathrm{mmol})$ was dissolved in hydrazine monohydrate $(7 \mathrm{~mL})$ and the mixture was heated to reflux for $4 \mathrm{~h}$. The solution was cooled down to room temperature and stored at $4{ }^{\circ} \mathrm{C}$ overnight. The sticky solid formed was isolated by filtration and then dissolved in $\mathrm{CH}_{2} \mathrm{Cl}_{2}(5 \mathrm{~mL})$. The solvent was evaporated and the oily residue was partitioned between $\mathrm{H}_{2} \mathrm{O}$ and $\mathrm{CHCl}_{3}(25 \mathrm{~mL}$ each). The 
aqueous phase was extracted with $\mathrm{CHCl}_{3}(3 \times 25 \mathrm{~mL})$. The combined organic extracts were dried with $\mathrm{MgSO}_{4}$, filtered, and the solvent evaporated to give $0.715 \mathrm{~g}$ of a yellowish oil that was used directly in the next step without further purification. Yield $0.650 \mathrm{~g}$, quant. ${ }^{1} \mathrm{H}$ NMR $\left(\mathrm{CDCl}_{3}, 300 \mathrm{MHz}, 25^{\circ} \mathrm{C}\right): \delta=6.48$ (s, $3 \mathrm{H}), 4.02$ (s, $6 \mathrm{H}), 3.0-1.8\left(\mathrm{~m}, 54 \mathrm{H}, \mathrm{CH}_{2}\right), 1.76\left(\mathrm{~s}, 9 \mathrm{H}, \mathrm{CH}_{3}\right) \mathrm{ppm} .{ }^{13} \mathrm{C} \mathrm{NMR}\left(\mathrm{CDCl}_{3}, 75 \mathrm{MHz}, 25^{\circ} \mathrm{C}\right): \delta=$ 137.4, 128.0, 76.5, 58.12, 53.0, 50.1, 43.7, 43.0 ppm. MALDI/ToF MS: $m / z=673.61$, calcd. for $[M+\mathrm{H}]^{+}$, 673.61. $\mathrm{C}_{36} \mathrm{H}_{72} \mathrm{~N}_{12}$ (673.05): calcd. C 64.24, H 10.78, N 24.97; found C 63.99, H 11.00, N 25.01.

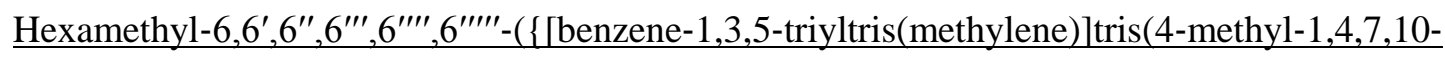
tetraazacyclododecane-10,1,7-triyl) \}hexakis(methylene))hexapicolinate (8)

Compound 7 (0.65 g, $0.97 \mathrm{mmol})$ was dissolved in dry acetonitrile $(30 \mathrm{~mL})$ and $\mathrm{K}_{2} \mathrm{CO}_{3}$ was added $(1.02 \mathrm{~g}$, $7.40 \mathrm{mmol})$. The mixture was heated at $40{ }^{\circ} \mathrm{C}$ and a solution of methyl 6-(chloromethyl)picolinate $(0.810 \mathrm{~g}$, $4.36 \mathrm{mmol})$ in dry acetonitrile $(30 \mathrm{~mL})$ was added dropwise over a period of $24 \mathrm{~h}$. The mixture was heated at $40{ }^{\circ} \mathrm{C}$ for one week, and then an additional amount of methyl 6-(chloromethyl)picolinate $(0.226 \mathrm{~g}, 1.22$ mmol) was added. The mixture was heated at $40{ }^{\circ} \mathrm{C}$ for $48 \mathrm{~h}$, and the excess $\mathrm{K}_{2} \mathrm{CO}_{3}$ was filtered off. The solvent was evaporated and the oily residue was partitioned between equal volumes of $\mathrm{H}_{2} \mathrm{O}$ and $\mathrm{CHCl}_{3}(25$ $\mathrm{mL})$. The aqueous phase was extracted with $\mathrm{CHCl}_{3}(3 \times 25 \mathrm{~mL})$. The combined organic extracts were dried with $\mathrm{MgSO}_{4}$, filtered, and the solvent removed in a rotary evaporator to give $1.32 \mathrm{~g}$ of a yellowish oil that was used directly in the next step without further purification. Yield $87 \%$. ${ }^{13} \mathrm{C} \mathrm{NMR}\left(\mathrm{CDCl}_{3}, 75 \mathrm{MHz}, 25\right.$ $\left.{ }^{\circ} \mathrm{C}\right): \delta=165.5,161.5,147.6,138.8,136.9,127.6,126.1,123.0,61.2,60.2,56.2,53.3,52.5,50.7,43.3 \mathrm{ppm}$. $\mathrm{C}_{84} \mathrm{H}_{114} \mathrm{~N}_{18} \mathrm{O}_{12} \cdot 5.5 \mathrm{CH}_{2} \mathrm{Cl}_{2}(2035.1)$ : calcd. C 52.82, H 6.19, N 12.39; found C 52.70, H 5.87, N 11.83.

$\left.\underline{6,6^{\prime}, 6^{\prime \prime}, 6^{\prime \prime \prime}-\{[(\{5-[(4-[(6-C a r b o x y p y r i d i n-2-y l) m e t h y l]-10-\{[6-(m e t h o x y c a r b o n y l) p y r i d i n-2-y l] m e t h y l ~}\right\}-7-$ methyl-1,4,7,10-tetraazacyclododecan-1-yl)methyl]-1,3-phenylene \}bis(methylene))bis(4-methyl-1,4,7,10-

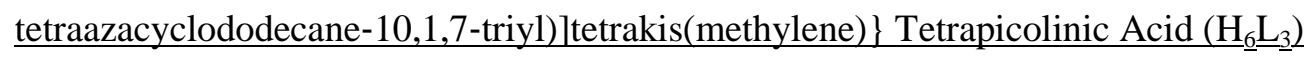

Compound 8 (0.300 g, $0.191 \mathrm{mmol})$ was dissolved in $6 \mathrm{~m} \mathrm{HCl}(10 \mathrm{~mL})$ and the resulting solution was heated at reflux overnight. Concentration of the solution afforded a yellowish solid that was characterized as $\mathrm{H}_{6} \mathbf{L}_{3} \cdot 18 \mathrm{HCl}$. Yield $0.409 \mathrm{~g}, 100 \%$. $\mathrm{C}_{78} \mathrm{H}_{102} \mathrm{~N}_{18} \mathrm{O}_{12} \cdot 16 \mathrm{HCl} \cdot 2 \mathrm{H}_{2} \mathrm{O}(2103.2)$ : calcd. C 44.54, H 5.85, N 11.99; found C 44.35, H 5.88, N 11.76. ${ }^{13} \mathrm{C}$ NMR $\left(\mathrm{D}_{2} \mathrm{O}, 75 \mathrm{MHz}, 25{ }^{\circ} \mathrm{C}\right): \delta=168.7,160.4,148.0,142.6,140.9$, $132.4,130.8,127.7,58.9,55.79,51.71,46.0 \mathrm{ppm}$.

\section{$\underline{\text { Eu and Tb Complexes }}$}

In a typical experiment, the ligand $\left(\mathrm{H}_{4} \mathbf{L}_{2}\right.$ or $\left.\mathrm{H}_{6} \mathbf{L}_{3}\right)$ and diisopropylethylamine (DIEA) were dissolved in $n$ butanol. A solution of $\mathrm{LnCl}_{3} \cdot 6 \mathrm{H}_{2} \mathrm{O}$ in $n$-butanol was slowly added and the mixture was heated at reflux for three days. The reaction mixture was evaporated to dryness, the crude residue dissolved in a minimum of water, and then addition of $\mathrm{CH}_{3} \mathrm{CN}$ resulted in the formation of a precipitate, which was collected by centrifugation and dried.

$\left[\mathrm{Tb}_{2} \underline{\mathrm{L}_{2}}\right] \mathrm{Cl}_{\underline{2}}$

Obtained from $\mathrm{H}_{4} \mathbf{L}_{2}(15.3 \mathrm{mg}, 15 \mu \mathrm{mol})$ and DIEA $(21 \mu \mathrm{L})$ in $5 \mathrm{~mL} n$-butanol and $\mathrm{TbCl}_{3} \cdot 6 \mathrm{H}_{2} \mathrm{O}(14 \mathrm{mg}, 37$ umol). Yield: $20 \mathrm{mg}, 95 \%$. $\mathrm{C}_{54} \mathrm{H}_{66} \mathrm{Cl}_{2} \mathrm{~N}_{12} \mathrm{O}_{8} \mathrm{~Tb}_{2} \cdot 13 \mathrm{H}_{2} \mathrm{O}$ (1634.1): calcd. C 39.69, H 5.67, N 10.29; found C 39.97, H 5.52, N 9.87. ESI ${ }^{+} / \mathrm{MS}\left(\mathrm{H}_{2} \mathrm{O}\right): \mathrm{m} / z$ calcd. for $\left[\mathrm{C}_{54} \mathrm{H}_{66} \mathrm{~N}_{12} \mathrm{O}_{8} \mathrm{~Tb}_{2}\right]^{2+}: 664.18$, found $664.18(100 \%)$.

$\underline{\left.\mathrm{Eu}_{2} \underline{\mathrm{L}}_{2}\right] \mathrm{Cl}_{2}}$

Obtained from $\mathrm{H}_{4} \mathbf{L}_{2}(12.2 \mathrm{mg}, 12 \mu \mathrm{mol})$ and DIEA $(21 \mu \mathrm{L})$ in $5 \mathrm{~mL} n$-butanol and $\mathrm{EuCl}_{3} \cdot 6 \mathrm{H}_{2} \mathrm{O}(14 \mathrm{mg}, 37$ $\mu \mathrm{mol})$. Yield: $12 \mathrm{mg}, 72 \%$. ESI ${ }^{+} / \mathrm{MS}\left(\mathrm{H}_{2} \mathrm{O}\right): \mathrm{m} / z$ calcd. for $\left[\mathrm{C}_{54} \mathrm{H}_{66} \mathrm{~N}_{12} \mathrm{O}_{8} \mathrm{Eu}_{2}\right]^{2+}: 657.18$, found 657.17 $(100 \%)$. 


\section{$\left[\mathrm{Tb}_{3} \underline{\mathrm{L}}_{3}\right]_{\mathrm{Cl}} \underline{\mathrm{H}_{3}}$}

Obtained from $\mathrm{H}_{6} \mathbf{L}_{3}(25.0 \mathrm{mg}, 12 \mu \mathrm{mol})$ and DIEA $(54 \mu \mathrm{L})$ in $3 \mathrm{~mL} n$-butanol and $\mathrm{TbCl}_{3} \cdot 6 \mathrm{H}_{2} \mathrm{O}(14.4 \mathrm{mg}, 39$

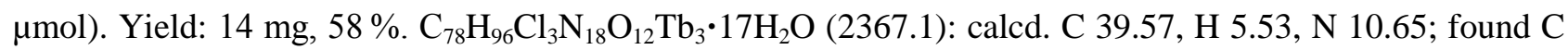
40.19, $\mathrm{H}$ 5.34, N 10.23. $\mathrm{ESI}^{+} / \mathrm{MS}\left(\mathrm{H}_{2} \mathrm{O}\right): \mathrm{m} / z$ calcd. for $\left[\mathrm{C}_{78} \mathrm{H}_{96} \mathrm{~N}_{18} \mathrm{O}_{12} \mathrm{~Tb}_{3}\right]^{3+}: 651.17$, found $651.17(100 \%)$.

\section{$\left[\mathrm{Eu}_{3} \underline{\underline{L}}_{3}\right]_{\mathrm{Cl}} \underline{\underline{3}}$}

Obtained from $\mathrm{H}_{6} \mathbf{L}_{3}(25.0 \mathrm{mg}, 12 \mu \mathrm{mol})$ and DIEA $(54 \mu \mathrm{L})$ in $3 \mathrm{~mL} n$-butanol and $\mathrm{EuCl}_{3} \cdot 6 \mathrm{H}_{2} \mathrm{O}(14.1 \mathrm{mg}, 38$ $\mu \mathrm{mol})$. Yield: $15 \mathrm{mg}, 61 \%$. ESI ${ }^{+} / \mathrm{MS}\left(\mathrm{H}_{2} \mathrm{O}\right): \mathrm{m} / \mathrm{z}$ calcd. for $\left[\mathrm{C}_{78} \mathrm{H}_{96} \mathrm{~N}_{18} \mathrm{O}_{12} \mathrm{Eu}_{3}\right]^{3+}: 645.17$, found 645.17 $(100 \%)$.

\section{Computational Details}

All calculations were performed by employing the Gaussian 09 package (Revision D.01) ${ }^{[48]}$ Geometry optimizations of the $\left[\mathrm{Eu}_{2} \mathbf{L}_{2}\right]^{2+}$ and $\left[\mathrm{Eu}_{3} \mathbf{L}_{3}\right]^{3+}$ systems were performed in aqueous solution at the Hartree-Fock (HF) level by using the large-core effective core potential (ECP) of Dolg et al. and the related [5s4p3d]-GTO valence basis set for the lanthanides, ${ }^{[49]}$ and the 3-21G basis set for $\mathrm{C}, \mathrm{H}, \mathrm{N}$, and $\mathrm{O}$ atoms. Although small, HF calculations employing this basis set in combination with the $f$-in-core ECP were shown to provide molecular geometries of $\mathrm{Ln}$ dota-like complexes (dota $=$ 1,4,7,10-tetraazacyclododecane-1,4,7,10-tetraacetic acid) in good agreement with the experimental structures observed by single-crystal X-ray diffraction studies. ${ }^{[50]}$ No symmetry constraints were imposed during the optimizations. In the case of the $\left[\mathrm{Eu}_{2} \mathbf{L}_{2}\right]^{2+}$ system, the optimization achieved full convergence, and thus the stationary point found on the potential energy surface was tested to represent an energy minima rather than a saddle point by frequency analysis. For $\left[\mathrm{Eu}_{3} \mathbf{L}_{3}\right]^{3+}$, full convergence could not be achieved, and for this reason frequency analysis was not performed to characterize the stationary point; thus, the final geometry corresponds to a stable conformation for the chosen minimization algorithm, rather than a true energy minimum. ${ }^{[51]}$ Solvent effects (water) were evaluated by using the integral equation formalism variant of the polarizable continuum model (IEFPCM) as implemented in Gaussian 09. ${ }^{[52]}$

\section{$\underline{\text { Spectroscopy }}$}

UV/Vis absorption spectra were recorded with a Perkin-Elmer lambda 950 spectrometer. Steady-state emission spectra were recorded with an Edinburgh Instrument FLP920 spectrometer working with a continuous $450 \mathrm{~W}$ Xe Lamp and a red sensitive photomultiplier in Peltier housing. All spectra were corrected for the instrumental functions. When necessary, a $399 \mathrm{~nm}$ cutoff filter was used to eliminate second-order artifacts. Phosphorescence lifetimes were measured on the same instrument working in the multi-channel spectroscopy (MCS) mode, by using a Xenon flash lamp as the excitation source. Luminescence quantum yields were measured according to conventional procedures, ${ }^{[53]}$ with optically diluted solutions (optical density $<0.05)$, by using rhodamine $6 \mathrm{G}$ in water $(\Phi=0.76)^{[54]}$ as a reference for $\mathrm{Tb}$ and $\left[\mathrm{Ru}(\mathrm{bipy})_{3}\right] \mathrm{Cl}_{2}$ in water $(\Phi=0.04$; bipy $=$ bipyridine $)$ for $E{ }^{[55]}$

\section{Acknowledgements}

M. S. and L. C. thank the French National Agency for Research for a grant through the NanoFRET project (ANR P2N 2012). The European COST action CM 1006 (EuFEN) is acknowledged for a short-term scientific mission for M. S. C. P.-I., and R. T. thank the invited Professor grant afforded to C. P.-I. by the University of Brest. C. P.-I and D. E.-G. thank the Centro de Supercomputación de Galicia (CESGA) for providing the computer facilities. Dr Minjie Zhao is gratefully acknowledged for her help in recording UPLC-MS and HPLC data. 


\section{References}

[1] L. D. Lavis and R. T. Raines, ACS Chem. Biol., 2008, 3, 142-155.

[2] I. L. Medintz, H. T. Uyeda, E. R. Goldman and H. Mattoussi, Nat. Mater., 2005, 4, 435-446.

[3] J. W. Walton, A. Bourdolle, S. J. Butler, M. Soulie, M. Delbianco, B. K. McMahon, R. Pal, H. Puschmann, J. M. Zwier, L. Lamarque, O. Maury, C. Andraud and D. Parker, Chem. Commun., 2013, 49, $1600-1602$.

[4] J. Xu, T. M. Corneillie, E. G. Moore, G. L. Law, N. G. Butlin and K. N. Raymond, J. Am. Chem. Soc., 2011, 133, 19900-19910.

[5] M. Starck, P. Kadjane, E. Bois, B. Darbouret, A. Incamps, R. Ziessel and L. J. Charbonnière, Chem. Eur. J., 2011, 17, 9164-9179.

[6] S. Quici, M. Cavazzini, G. Marzanni, G. Accorsi, A. Armaroli, B. Ventura and F. Barigelletti, Inorg. Chem., 2005, 44, 529-537.

[7] H. J. Tanke, J. Microsc., 1989, 155, 405-418.

[8] M. Sy, A. Nonat, N. Hildebrandt and L. J. Charbonnière, Chem. Commun., 2016, 52, 5080-5095.

[9] J.-C. G. Bünzli, Coord. Chem. Rev., 2015, 293-294, 19-47.

[10] A. Beeby, I. M. Clarkson, R. S. Dickins, S. Faulkner, D. Parker, L. Royle, A. S. de Sousa, J. A. G. Williams and M. Woods, J. Chem. Soc., Perkin Trans. 2, 1999, 493-504.

[11] W. D. W. HorrocksJr and D. Sudnick, J. Am. Chem. Soc., 1979, 101, 334-340.

[12] C. Doffek, N. Alzakhem, C. Bischof, J. Wahsner, T. Güden-Silber, J. Lügger, C. Platas-Iglesias and M. Seitz, J. Am. Chem. Soc., 2012, 134, 16413-16423.

[13] C. Doffek, J. Wahsner, E. Kreidt and M. Seitz, Inorg. Chem., 2014, 53, 3263-3265.

[14] M. Latva, H. Takalo, V.-M. Mukkala, C. Matachescu, J. C. Rodriguez-Ubis and J. Kankare, J. Lumin., 1997, 75, 149-169.

[15] F. J. Steemers, W. Verboom, D. N. Reinhoudt, E. B. van der Tol and J. W. Verhoeven, J. Am. Chem. Soc., 1995, 117, 9408-9414.

[16] A. D'Aléo, A. Picot, P. L. Baldeck, C. Andraud and O. Maury, Inorg. Chem., 2008, 47, 10269-10279.

[17] N. Hildebrandt, L. J. Charbonnière and H.-G. Löhmannsröben, J. Biomed. Biotechnol., 2007, 7916979175.

[18] J.-A. Yu, J. Lumin., 1998, 78, 265-270.

[19] E. Debroye and T. N. Parac-Vogt, Chem. Soc. Rev., 2014, 43, 8178-8192.

[20] M. Jauregui, W. S. Perry, C. Allain, L. R. Vidler, M. C. Willis, A. M. Kenwright, J. S. Snaith, G. J. Stasiuk, M. P. Lowe and S. Faulkner, Dalton Trans., 2009, 6283-6285.

[21] D. J. Lewis, P. B. Glover, M. C. Solomons and Z. Pikramenou, J. Am. Chem. Soc., 2011, 133, 10331043. 
[22] M. Regueiro-Figueroa, A. Nonat, A. R. Gabriele, D. Esteban-Gómez, A. de Blas, T. Rodríguez-Blas, L. J. Charbonniere, M. Botta and C. Platas-Iglesias, Chem. Eur. J., 2013, 19, 11696-11706.

[23] R. I. Mc Donald, J. Biol. Chem., 1990, 265, 13533-13539.

[24] L. J. Charbonnière, J.-L. Rehspringer, R. Ziessel and Y. Zimmermann, New J. Chem., 2008, 32, 10551059 .

[25] J. Goetz, A. Nonat, A. Diallo, M. Sy, I. Sera, A. Lecointre, C. Lefevre, C. F. Chan, K. L. Wong and L. J. Charbonnière, ChemPlusChem, 2016, 81, 526-534.

[26] F. Auzel and P. Goldner, Opt. Mater., 2001, 16, 93-103.

[27] F. Auzel, J. Lumin., 2002, 100, 125-130.

[28] G. Chen, H. Qiu, P. N. Prasad and X. Chen, Chem. Rev., 2014, 114, 5161-5214.

[29] Y. Suffren, B. Golesorkhi, D. Zare, L. Guenee, H. Nozary, S. V. Eliseeva, S. Petoud, A. Hauser and C. Piguet, Inorg. Chem., 2016, 55, 9964-9972.

[30] A. Nonat, C. F. Chan, T. Liu, C. Platas-Iglesias, Z. Liu, W. T. Wong, W. K. Wong, K. L. Wong and L. J. Charbonnière, Nature Commun., 2016, 7, 11978.

[31] A. Rodríguez-Rodríguez, D. Esteban-Gómez, A. de Blas, T. Rodríguez-Blas, M. Fekete, M. Botta, R. Tripier and C. Platas-Iglesias, Inorg. Chem., 2012, 51, 2509-2521.

[32] A. Rodríguez-Rodríguez, D. Esteban-Gómez, A. de Blas, T. Rodríguez-Blas, M. Botta, R. Tripier and C. Platas-Iglesias, Inorg. Chem., 2012, 51, 13419-13429.

[33] A. Rodríguez-Rodríguez, Z. Garda, E. Ruscsak, D. Esteban-Gómez, A. de Blas, T. Rodríguez-Blas, L. M. P. Lima, M. Beyler, R. Tripier, G. Tircsò and C. Platas-Iglesias, Dalton Trans., 2015, 44, 5017-5031.

[34] J. Rohovec, R. Gyepes, I. Cisarova, J. Rudovsky and I. Lukes, Tetrahedron Lett., 2000, 41, 1249-1253.

[35] M. Mato-Iglesias, A. Roca-Sabio, Z. Palinkas, D. Esteban-Gómez, C. Platas-Iglesias, E. Toth, A. de Blas and T. Rodríguez-Blas, Inorg. Chem., 2008, 47, 7840-7851.

[36] A. Rodríguez-Rodríguez, D. Esteban-Gómez, R. Tripier, G. Tircsò, Z. Garda, I. Toth, A. de Blas, T. Rodríguez-Blas and C. Platas-Iglesias, J. Am. Chem. Soc., 2014, 136, 17954-17957.

[37] N. Chatterton, Y. Bretonnière, J. Pécaut and M. Mazzanti, Angew. Chem. Int. Ed., 2005, 44, 7595-7598; Angew. Chem., 2005, 117, 7767-7770.

[38] M. Regueiro-Figueroa, B. Bensenane, E. Ruscsak, D. Esteban-Gómez, L. J. Charbonnière, G. Tirsco, I. Toth, A. de Blas, T. Rodríguez-Blas and C. Platas-Iglesias, Inorg. Chem., 2011, 50, 4125-4141.

[39] C. H. Kline and J. Turkevich, J. Chem. Phys., 1944, 12, 300-309.

[40] N. S. Gill, R. H. Nuttall, D. E. Scaife and D. W. A. Sharp, J. Inorg. Nucl. Chem., 1961, 18, 79-87.

[41] S. V. Eliseeva and J.-C. G. Bünzli, Chem. Soc. Rev., 2010, 39, 189-227.

[42] M. H. V. Werts, R. T. F. Jukes and J. W. Verhoeven, Phys. Chem. Chem. Phys., 2002, 4, 1542-1548.

[43] G. Nocton, A. Nonat, C. Gateau and M. Mazzanti, Helv. Chim. Acta, 2009, 92, 2257-2273. 
[44] C. Guanci, G. Giovenzanna, L. Lattuada, C. Platas-Iglesias and L. J. Charbonnière, Dalton Trans., 2015, 44, 7654-7661.

[45] A. Zaïm, S. V. Eliseeva, L. Guénée, H. Nozary, S. Petoud and C. Piguet, Chem. Eur. J., 2014, 20, 12172-12182.

[46] A. Nonat, M. Regueiro-Figueroa, D. Esteban-Gómez, M. A. de Blas, T. Rodríguez-Blas, C. PlatasIglesias and L. J. Charbonnière, Chem. Eur. J., 2012, 18, 8163-8173.

[47] H. E. Gottlieb, V. Kotlyar and A. Nudelman, J. Org. Chem., 1997, 62, 7512-7515.

[48] M. J. Frisch, G. W. Trucks, H. B. Schlegel, G. E. Scuseria, M. A. Robb, J. R. Cheeseman, G. Scalmani, V. Barone, B. Mennucci, G. A. Petersson, H. Nakatsuji, M. Caricato, X. Li, H. P. Hratchian, A. F. Izmaylov, J. Bloino, G. Zheng, J. L. Sonnenberg, M. Hada, M. Ehara, K. Toyota, R. Fukuda, J. Hasegawa, M. Ishida, T. Nakajima, Y. Honda, O. Kitao, H. Nakai, T. Vreven, J. A. MontgomeryJr, J. E. Peralta, F. Ogliaro, M. Bearpark, J. J. Heyd, E. Brothers, K. N. Kudin, V. N. Staroverov, R. Kobayashi, J. Normand, K. Raghavachari, A. Rendell, J. C. Burant, S. S. Iyengar, J. Tomasi, M. Cossi, N. Rega, J. M. Millam, M. Klene, J. E. Knox, J. B. Cross, V. Bakken, C. Adamo, J. Jaramillo, R. Gomperts, R. E. Stratmann, O. Yazyev, A. J. Austin, R. Cammi, C. Pomelli, J. W. Ochterski, R. L. Martin, K. Morokuma, V. G. Zakrzewski, G. A. Voth, P. Salvador, J. J. Dannenberg, S. Dapprich, A. D. Daniels, Ö. Farkas, J. B. Foresman, J. V. Ortiz, J. Cioslowski and D. J. Fox, Gaussian 09, Revision D.01, Gaussian, Inc., Wallingford CT, 2009.

[49] M. Dolg, H. Stoll, A. Savin and H. Preuss, Theor. Chim. Acta, 1989, 75, 173-194.

[50] U. Cosentino, A. Villa, D. Pitea, G. Moro, V. Barone and A. Maiocchi, J. Am. Chem. Soc., 2002, 124, 4901-4909.

[51] U. Cosentino, D. Pitea, G. Moro, V. Barone, A. Villa, R. N. Muller and F. Botteman, Theor. Chem. Acc., 2004, 111, 204-209.

[52] J. Tomasi, B. Mennucci and R. Cammi, Chem. Rev., 2005, 105, 2999-3094.

[53] B. Valeur, in: Molecular Fluorescence, Wiley-VCH, Weinheim, 2002.

[54] J. Olmsted, J. Phys. Chem., 1979, 83, 2581-2584.

[55] H. Ishida, S. Tobita, Y. Hasegawa, R. Katoh and N. Noaki, Coord. Chem. Rev., 2010, 254, 2449-2458.

\footnotetext{
${ }^{\mathrm{i}}$ Supporting information for this article is available online: https://doi.org/10.1002/ejic.201601516.
} 